\title{
Charge Variants Analysis of Recombinant Monoclonal Antibodies
}

\author{
Fatemeh Torkashvand and Behrouz Vaziri* \\ Biotechnology Research Center, Pasteur Institute of Iran, Iran \\ *Corresponding author: Behrouz Vaziri, Biotechnology Research Center, Pasteur Institute of Iran, Tehran, Iran
}

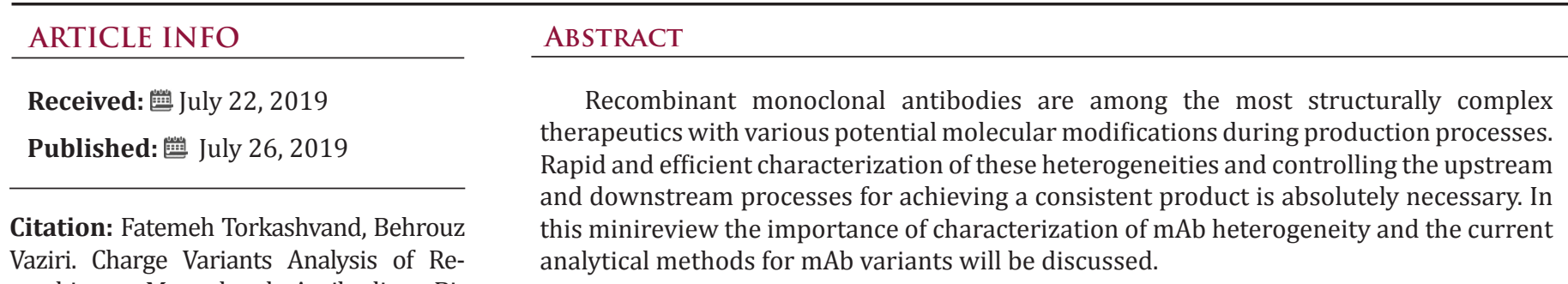
combinant Monoclonal Antibodies. Biomed J Sci \& Tech Res 20(1)-2019. BJSTR. MS.ID.003395.

\section{Introduction}

Recombinant monoclonal antibodies (mAbs) are the most approved biopharmaceuticals, as new drugs or biosimilars, between 2015 and 2018 [1]. These magic bullets target biological molecules with crucial role in severe and chronic diseases such as cancer, autoimmune, cardiovascular, respiratory, hematology, and infectious diseases [2]. They have incredible therapeutic and commercial value which make them among the top 10 best sellers of pharmaceuticals for several past years [1]. Chinese Hamster Ovary (CHO) cell lines are the mostly used mammalian host for mAb production. These cell lines are well characterized and experienced by many manufacturers, so the knowledge about their production behavior from high expression capability to desirable post translational modifications made them almost irreplaceable by alternative cell lines [3]. The complexity of mAb with about $150 \mathrm{kDa}$ molecular weight make the implementation of quality by design (QbD) as an unavoidable strategy for development and manufacturing of these molecules [4]. QbD defines the critical quality attributes and a control strategy to assure the stable and consistent quality during the manufacturing process. Different post translational modifications during upstream process such as amino or carboxy terminal processing and glycosylation or during downstream processes or storage, such as deamidation, oxidation and fragmentation will end to different variants which could affect the safety, quality and efficacy of mAbs [5].Therefore, characterization and quantification of mAbs charge variants are required for assessing a consistent product quality [6]

\section{Methods of mAb Charge Variant Analysis}

Analytical methods with capability to separate differently charged molecules are used to characterize the variants of mAbs. The using of fast, reliable, and quantitative analytical methods is necessary for this purpose [7]. Charge- based variants have been categorized as acidic, main, and basic species. Main species of mAbs usually contains three PTMs including N-pyroGlu of either or both of the light and heavy chains, heavy chain(s) Lys-C removal, and glycosylation of the Asn residue in the $\mathrm{CH} 2$ domain with neutral oligosaccharides [8]. Chromatographic and electrophoretic tools include ion exchange chromatography (IEX) and isoelectric focusing (IEF), are the most common and simple analytical methods for the analysis of mAbs charge heterogeneities [9-11]. IEF may help to visualize the charge isoforms, but chromatographic tools are more appropriate for precise quantification [12].

Cation exchange chromatography (CEX), has been a standard method for the characterization of mAbs charge heterogeneity and routinely used as a fingerprint of the distribution of posttranslational modifications present on the mAb, also CEX analysis is necessary for mAbs quality control analysis and requested by regulatory [13]. When higher resolution is required to resolve all protein variants, 
improved techniques, such as capillary zone electrophoresis (CZE), capillary isoelectric focusing (cIEF), imaging isoelectric focusing (icIEF), micro liquid chromatography, and two-dimensional electrophoresis can be useful [14-16]. Two-dimensional liquid chromatography (2D-LC) coupled with mass spectrometry can produce an excellent resolution for identification of individual charge variants. The analytical methods include cIEF, CEX, LC -MS and tryptic peptide mapping can be used to analyze and identify C-terminal and $\mathrm{N}$-terminal charge variants [14]. It was reported that LC -MS after trypsin digestion is the most useful and precise analytical method for C-terminal variant analysis in comparison to other methods.

Also, an orthogonal method such as MALDI-TOF (Matrix-assisted laser desorption/ionization time of flight), ESI-TOF (Electrospray ionization time of flight), or ion chromatography should be used to measure relative percentages of $\mathrm{mAb}$ isoforms including 0,1 or 2 C-terminal lysines [17]. The gold standard for precise analysis of charge variants is peptide mapping followed by RP-HPLC-MS/ MS. Huang et al. used protein sample digestion with trypsin and Glu-C sequentially, followed by RP-HPLC-MS/MS analysis to study the humanized IgG1 mAb [18]. There are different methods for evaluating the variant species of therapeutic mAbs. The depth of the knowledge prepared by these methods are different and they could be used in various stages of developing, establishment the production process, and releasing the formulated products.

\section{References}

1. Walsh G (2018) Biopharmaceutical benchmarks 2018. Nat Biotechnol 36(12): 1136-1145.

2. Singh S ,Kumar NK, Dwiwedi P, Charan J, Kaur R, Sidhu P (2018) Monoclonal Antibodies: A Review Curr Clin Pharmacol 13(2): 85-99.

3. Kelley B, R Kiss, M Laird (2018) A Different Perspective: How Much Innovation Is Really Needed for Monoclonal Antibody Production Using Mammalian Cell Technology? Adv Biochem Eng Biotechnol 165: 443462.

4. Finkler C, L Krummen (2016) Introduction to the application of QbD principles for the development of monoclonal antibodies. Biologicals 44(5): 282-290.

5. Vanam RP, MA Schneider, and M Marlow (2015) Rapid quantitative analysis of monoclonal antibody heavy and light chain charge heterogeneity MAbs 7(6): 1118-1127.

\section{ISSN: 2574-1241}

DOI: 10.26717/BJSTR.2019.20.003395

Behrouz Vaziri. Biomed J Sci \& Tech Res

This work is licensed under Creative

Commons Attribution 4.0 License

Submission Link: https://biomedres.us/submit-manuscript.php
6. Torkashvand F and B Vaziri (2017) Main Quality Attributes of Monoclonal Antibodies and Effect of Cell Culture Components. Iranian biomedical journal 21(3): 131-141.

7. Trappe A, Füssl F, Carillo S, Zaborowska I, Meleady P (2018) Rapid charge variant analysis of monoclonal antibodies to support lead candidate biopharmaceutical development. J Chromatogr B Analyt Technol Biomed Life Sci 1095: 166-176.

8. Du Y, Walsh A, Ehrick R, Xu W, May K (2012) Chromatographic analysis of the acidic and basic species of recombinant monoclonal antibodies. MAbs 4(5): 578-585.

9. El Rassi Z (2010) Electrophoretic and electrochromatographic separation of proteins in capillaries: an update covering 2007-2009. Electrophoresis 31(1): 174-191.

10. Lin JQ Tan, S Wang (2011) A high-resolution capillary isoelectric focusing method for the determination of therapeutic recombinant monoclonal antibody. Journal of separation science 34(14): 1696-1702.

11. Meert CD, Lowell J Brady, Amy Guo, Alain Balland (2010) Characterization of antibody charge heterogeneity resolved by preparative immobilized pH gradients. Analytical chemistry 82(9): 3510-3518.

12. Du Y, Walsh A, Ehrick R, Xu W, May K (2012) Chromatographic analysis of the acidic and basic species of recombinant monoclonal antibodies in MAbs 4(5): 578-585.

13. Alekseychyk L, Su C, Becker GW, Treuheit MJ, Razinkov VI (2017) HighThroughput Screening and Analysis of Charge Variants of Monoclonal Antibodies in Multiple Formulations. SLAS DISCOVERY: Advancing Life Sciences R\&D 22(8): 1044-1052.

14. Brorson K, AY Jia (2014) Therapeutic monoclonal antibodies and consistent ends: terminal heterogeneity, detection, and impact on quality. Current opinion in biotechnology 30: 140-146.

15. Goyon A, Francois YN, Colas O, Beck A, Veuthey JL (2018) High-resolution separation of monoclonal antibodies mixtures and their charge variants by an alternative and generic CZE method. Electrophoresis 39(16): 2083-2090.

16. Stoll D, Danforth J, Zhang K, Beck A (2016) Characterization of therapeutic antibodies and related products by two-dimensional liquid chromatography coupled with UV absorbance and mass spectrometric detection. Journal of Chromatography B 1032: 51-60.

17. Dick LW Jr, Qiu D, Mahon D, Adamo M, Cheng KC (2008) C-terminal lysine variants in fully human monoclonal antibodies: Investigation of test methods and possible causes. Biotechnology and bioengineering 100(6): 1132-1143.

18. Ponniah G, Kita A, Nowak C, Neill A, Kori Y, Rajendran S (2015) Characterization of the acidic species of a monoclonal antibody using weak cation exchange chromatography and LC-MS. Analytical chemistry 87(17): 9084-9092.

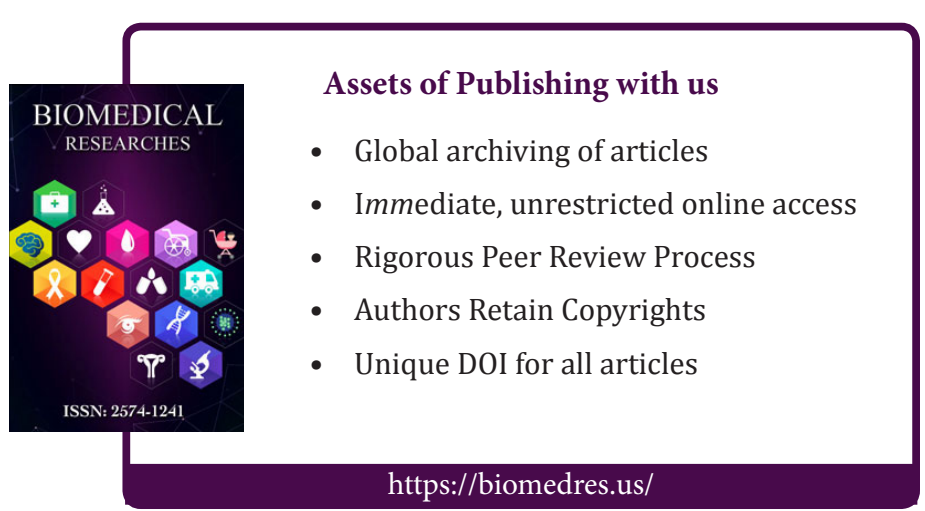

